\title{
A SURVEY OF INJURIES IN A 1st CLASS RUGBY UNION FOOTBALL CLUB \\ from 1972 - 1976
}

\author{
Dr T. E. DURKIN, M.B., Ch.B., M.R.C.G.P. \\ Hon. Medical Officer, Gloucester R.F.C. \\ Clinical Assistant - Orthopaedics, Gloucester Royal Hospital
}

\section{HISTORICAL NOTE}

Rugby football has been played in Gloucester for over one-hundred years and for the past eighty six at the present ground - Kingsholm situated centrally in a traditional Cathedral City which is rapidly expanding with the introduction of light industry in the post war years.

The game and club are very much part of the local scene as the majority of the players have family ties with the club stretching back three and even four generations. Similarly, the supporters of the club are steeped in local knowledge of the game and past players' achievements.

There have been two deaths attributable to playing in the history of the club. First in 1925 due to a ruptured kidney and the second in 1926 due to. a fractured cervical vertebra.

\section{MEDICAL ORGANISATION}

There is a fully equipped medical treatment room on the ground with full facilities for minor surgery under reasonable sterile conditions, and for emergency treatment of fractures. Examination couches, lighting and antiseptic washing arrangements are adequate. Stretchers and spinal boards, inflatable limb splints and wide range of bandaging materials collar and cuff slings etc.

Simple diagnostic instruments including stethoscope, auriscope, ophthalmoscope, sphygmomanometer and urinalysis set including hemastix for detection of blood in urine is available.

A personal file-card index system is used to record every player's injuries in detail. A wall chart schedule for anti-tetanus immunisation and booster injections of each. player has been found to serve a useful purpose.

Infrared and ultrasonic equipment is provided and treatment is given by a qualified physiotherapist and a doctor on training sessions twice weekly. A doctor is present at every game, assisted by a fully qualified Firstaid trainer and local St. John's Ambulance personnel. The general hospital accident unit is situated nearby the ground and close co-operation is maintained with the staff and Orthopaedic Dept.

\section{SCOPE OF THE SURVEY}

Approximately 50 first-class games are played on Kingsholm each season a proportion being under floods? lights in mid-winter.

The opposing teams are drawn from well-known re gions of Rugby Football: South Wales, the Midlandso South-West England and London, in a representative proportion. As they are all players from first-class clubs $>$ many have also received International recognition.

There are then approximately 1,500 player $\vec{\ominus}$ apperances involved in the game at this high club level at Kingsholm each season, making a total of about 6,000 af risk during this four year survey from 1972-76.

Age range is from 19-34 with the median range beo tween 25-30 years. In a pilot survey it was not evident that there was any incidence of injury relative to age $\overrightarrow{\vec{b}}$ and this has not been considered as a worthwhile factor $\frac{3}{3}$

Players are drawn from social groups I-V with pre dominance in Group III and IV. The majority are mari ried in full-time employment and loss of work-time duen to injury in an amateur sport is a risk that they accept as part of their enjoyment and participation in the game of Rugby Football.

\section{RELATIONSHIP OF INJURY AND POSITION}

This relationship has been used in previous surveys to indicate high risk injury positions and has been includeo for this reason.

\section{ARTIFICIAL LIGHTING}

In the winter months from cessation of British Sum mer Time (3rd week October to 3rd week in March) games may be played at least partially under artificial light in midweek.

It was decided not to consider this factor because of the different proportions of games played under arti ficial light and also indeed the variation of periods of 
individual matches played under natural and artificial light.

\section{DEFINITION}

For inclusion in this analysis, a rugby injury is defined as one which will cause a player to be unfit for selection for two consecutive weeks, making in all an absence of three weeks between competitive games.

Injuries have been divided into five main groups:-

1. Lacerations.

2. Fractures.

3. Soft Tissue Injuries.

4. Dislocations.

5. Concussion.

1. Lacerations have been sub-divided into facial or non-facial as they form a large group. Minor lacerations requiring two or three sutures are not included, for by definition above they usually do not prevent a player from training, or playing, for more than one or two weeks. Lacerations of the scalp, or hair-bearing area, have been excluded as they do not prevent a player participating for less than two weeks provided adequate protection by bandaging is provided before the game. The site of the head or facial lacerations has to be related to the playing position in the assessment of the period of unfitness; thus the speed of recovery to playing fitness in a laceration of the upper orbital margin or of the pinna of the ear of a forward, would be quite different from that of a wing three-quarter, who is less likely to sustain further injury by friction in scrummaging..

2. Fractures By definition a fracture is a radiological diagnosis be it a small bone of the hand or foot or a major limb bone; any of these would prevent resumption of playing for at least three weeks.

3. Soft Tissue Injuries comprise ligamentous injuries around joints, e.g. the ankle, knee, elbow, wrist, shoulder, musculo-tendinous injuries, e.g. traumatic damage to quadriceps, hamstrings or scapular muscles, and haematomata.

4. Dislocations Shoulder joint, acromio-clavicular joint and metacarpal joints are those mainly involved in this series and prudently would satisfy the definition of a serious injury.

5. Concussion This is considered as a period of unconsciousness of one minute or more, or if the period is ill-defined, a state of amnesia, unsteadiness and confusion with or without overt neurological phenomena requiring hospital observation for the succeeding 24 hours.
Discussion In this analysis of major rugby injuries, as previously defined there were a total of 88 from 211 matches between the years $1972-76$ involving over 6,000 player appearances.

These injuries have been classified into five main groups as shown with the following percentages:-

1. Lacerations

$35.2 \% \stackrel{\mathbb{1}}{\circ}$

2. Fractures

3. Soft Tissue injury

4. Dislocations

5. Concussion $27.2 \%$ ڤ $23.9 \%$

The relationship of major injury to position is shown as follows:-

$\begin{aligned} \text { 1. } & \text { Centre three quarters } \\ \text { 2. } & \text { Wing three quarters } \\ \text { 3. } & \text { Wing forwards } \\ \text { 4. } & \text { Prop forwards } \\ \text { 5. } & \text { Full back } \\ \text { 6. } & \text { No. } 8 \text { forward } \\ \text { 7. } & \text { Outside half } \\ \text { 8. } & \text { Hooker } \\ 9 . & \text { Scrum half } \\ \text { 10. } & \text { Lock forward }\end{aligned}$

16.

14.

14.

11.

9.

8.

6.

4

3.

3.

However it must be understood that in the game of Rugby Union Football comprising fifteen players there are two centre three quarters, two wing three quarters, two wing forwards and two lock forwards. Therefore when these injuries are corrected to individual players in their respective positions the average picture would appear as follows:-

1. Full back

2. Centre three quarter

3. No. 8 forward

4. Wing three quarter

5. Wing forward

6. Outside half

7. Prop forward

8. Hooker

9. Scrum half

10. Lock forward

9.

8.

8.

7.

7.

6.

5.5

4.

3.

1.5

\section{LACERATIONS}

There were 31 lacerations as defined, representing $35.2 \%$ of the total. These were mainly to the face and scalp and were caused by many different traumatic methods.

The incidence of $67.7 \%$ of all lacerations being facial or to the scalp compared to others, mainly on the upper and lower limbs, is noticeable. There was negligible incidence of secondary infection, healing occuring by pri- 
mary intention in the majority of lesions within two weeks. This result was achieved by the provision by the Club of a first class treatment room equipped with minor surgical instruments, steriliser, presterilised suture and dressing materials for immediate repair of lacerations on the players retirement from the playing field.

The lacerations were cleansed adequately, and sutured under conditions approaching asepsis with black silk. Occasionally a deep wound required the superficial fascia to be closed with fine gauge catgut prior to skin suturing and cutaneous dressing.

Home players have complete cover against tetanus infection by a follow-up system of booster injections and any visiting player without cover is given a booster of anti tetanus toxoid.

All lacerations to home players were inspected after 48 hours for signs of healing, and visiting players were informed to consult their own G.P. or Club doctor after a similar interval.

\section{FRACTURES}

There were 24 fractures representing $27.2 \%$ of the total injuries. The bones involved in the survey of fractures are as follows:-

$\begin{array}{ll}\text { 1. Major limb bones - } & \text { Radius } \\ \text { Tibia } & 3 . \\ \text { Fibula } & \text { Clavicle } \\ \text { 2. Bones of hand and wrist } & 3 . \\ \text { 3. Bones of foot and ankle } & 3 . \\ \text { 4. Nasal bones } & 7 . \\ \text { 5. Spinal } & 3 . \\ \end{array}$

All fractures were of the closed variety and only one, a radius, required open reduction and plating.

Mention should be made of the one severe injury in this series, an undisplaced fracture of the odontoid process of the 2nd cervical vertebra, the axis, to an experienced centre three quarter whilst tackling his opposite number round the thigh. He made a complete recovery and has played for the past two subsequent seasons at first team and county level. This was the only spinal fracture which occurred within the survey of 1972-76.

\section{SOFT TISSUE INJURIES}

There were 21 representing $23.9 \%$ of the total.

These were fairly constant in occurence and the majority were inversion sprains of the ligaments of the ankle joint without bone damage, several requiring im- mobilisation in P.O.P. for two or three weeks. Also $\frac{\text { के }}{2}$ included were complex injuries to knee joints involving $z$ menisci, collateral and cruciate ligaments, two eventually $\stackrel{\mathbb{Q}}{?}$ requiring meniscectomy.

The remainder consisted of intramsucular haematomata of the thigh from direct trauma, tendinous injuries of hamstrings and tendo Achilles, and finally two hyperextensions of the neck, one to a full back and one to an $\triangle$ outside half.

The low incidence of soft tissue injuries i.e. $23.9 \%$ is mainly due to the provision by the Club of immediate treatment following such an injury. This is accomplished by the application of ice-packs using cryogel methods followed by ultra-sonic therapy.

This is repeated at least twice daily for several days following the injury to endeavour to inhibit the inflammatory reaction to the greatest possible degree and so $\frac{}{3}$ facilitate early movement. This intensive treatment is carried out jointly by the club doctor, physiotherapist $\frac{7}{0}$ and trainer.

\section{DISLOCATIONS}

There were 7 representing $8 \%$ of the total.

These were mainly around the shoulder joint, three occuring in the acromio-clavicular joint, two to the gleno-humeral joint without associated fracture, and the other two to metacaral joints. There were no dislocations of the elbow joint or any joint of the lower limb.

\section{CONCUSSION}

There were 5 representing $5.7 \%$ of the total.

Out of five concussions, no fewer than four occurred in the past season 1975-76 to players in differing posi-을 tions. It is obviously difficult to ascertain the actual $D$ cause of this type of injury as evidence can only be gained from witnesses involved in the play at the time. N

However the 75-76 season has been exceptionally dry following a dry summer making for a hard playing surface and this may have contributed to the increase of concussion in this season by players striking their heads on the ground when tackled.

\section{SUMMARY}

In the relationship of injury to position the full back $\frac{\Omega}{\mathbb{D}}$ would appear to be most at risk followed closely by centre three quarters, No. 8 forward, wing three quarter and wing forwards. 
Scrum half and lock forwards seem to be less likely to injury in this survey.

Out of the total of 88 major injuries between 1972-76 the annual rate was as follows:-

1972.73

1973-74

12

1974-75

1975-76

These figures therefore show only a slight increase in major injuries over these years as shown on accompanying graph.

As a whole the back division of the teams sustained $54.5 \%$ of injuries and the forwards $45.5 \%$ showing a fairly even injury risk rate to position between backs and forwards.

Home players suffered $60.2 \%$ of the total injuries and visiting players $39.8 \%$.

Hospital referral, including those for radiological examination was $46.6 \%$ of the total injured and of these $\mathbf{8 . 5 \%}$ necessitated admission for $\mathbf{2 4}$ hours or more.

\section{CONCLUSION}

From the results of this analysis of major rugby injuries it is shown that the occurrence of this type of injury, as defined, is of the rate of one injury per two or three matches.

The injuries grouped under the titles of concussion, fractures and dislocation obviously require prompt hospital treatment though their rehabilitation to playing fitness can be aided by facilities provided by the club.

Lacerations and soft-tissue injuries which do not require hospital referral can often be treated more efficiently and rapidly at club treatment room level.

As in all forms of sport injuries, length of the period of enforced inactivity to the injured athlete is directly related to the time he will take to regain peak fitness. By using basic physiotherapy methods or immediate treatment to these latter two types of injury, the playing time cost to the player and Club can be shortened.

The severity of these injuries and their immediate care impose a responsibility on the host Club for provision of experienced and qualified medical attention and facilities to be available at every first class ground where Rugby Football is played. There should also be a co-operative follow-up between Club Doctor, G.P. and Hospital Orthopaedic and Physiotherapy Department to ensure a prudent and rapid return to the game of Rugby Union Football by the injured player.

\section{ACKNOWLEDGEMENTS}

My thanks for their assistance in preparation of this paper goes to: Mr. R. A. C. Davies, F.R.C.S., Orthopaedic Surgeon, Gloucester Royal Hospital, Mr. J. $\stackrel{\text { ? }}{+}$ Archer, M.A., D.P.E., Director of Physical Education, St. T Pauls College, Cheltenham, Mrs. Griffiths, M.C.S.P., Physiotherapist, Gloucester Royal Hospital, Mr. J. Fryer, Trainer, Gloucester Rugby Football Club, and Mr. R. G. Long, Secretary Gloucester Rugby Football Club.

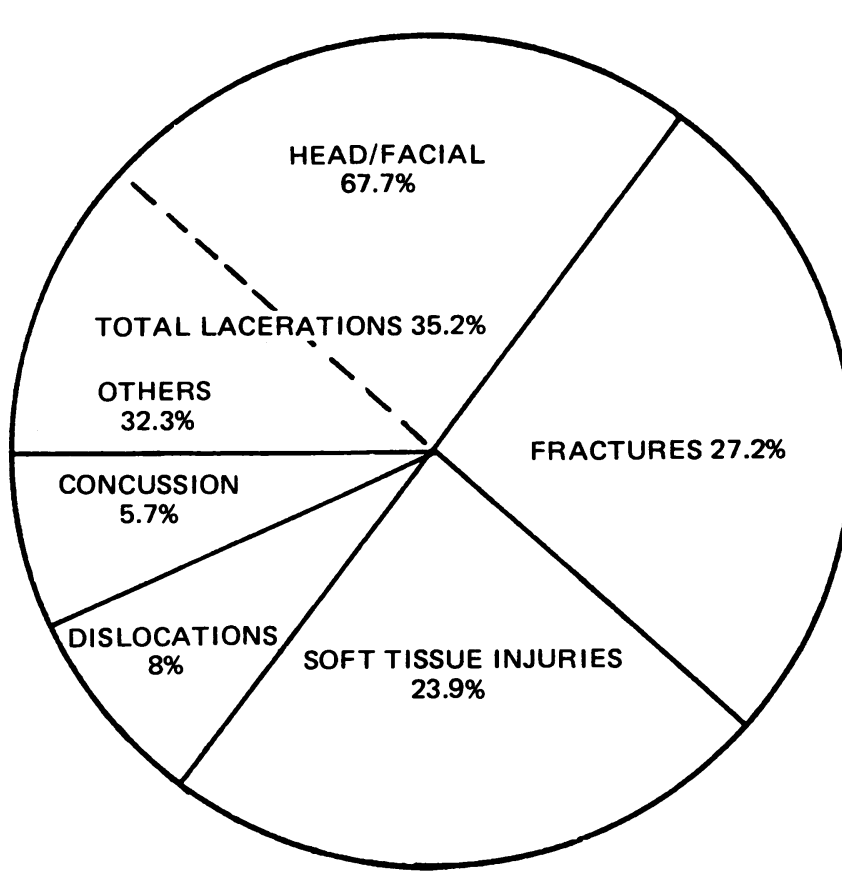

Fig. 1. Diagrammatic representation of total major in- $\frac{3}{0}$ juries at Kingsholm Rugby Football Ground, during seasons 1972-1976

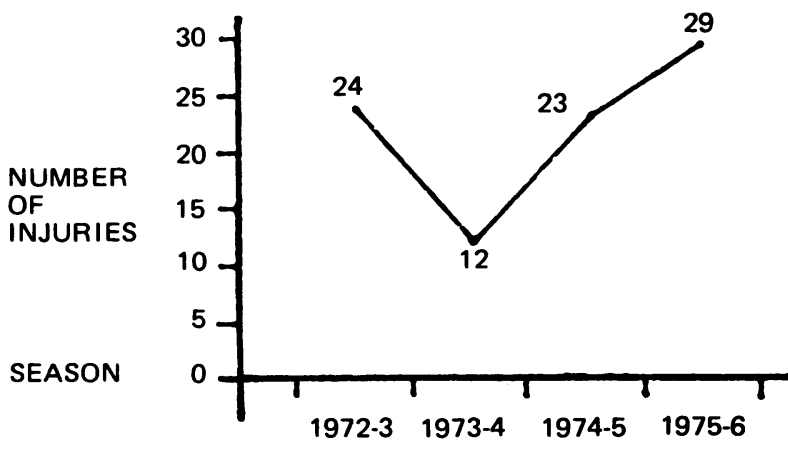

Fig. 2. Injuries at Kingsholm, 1972-1976 

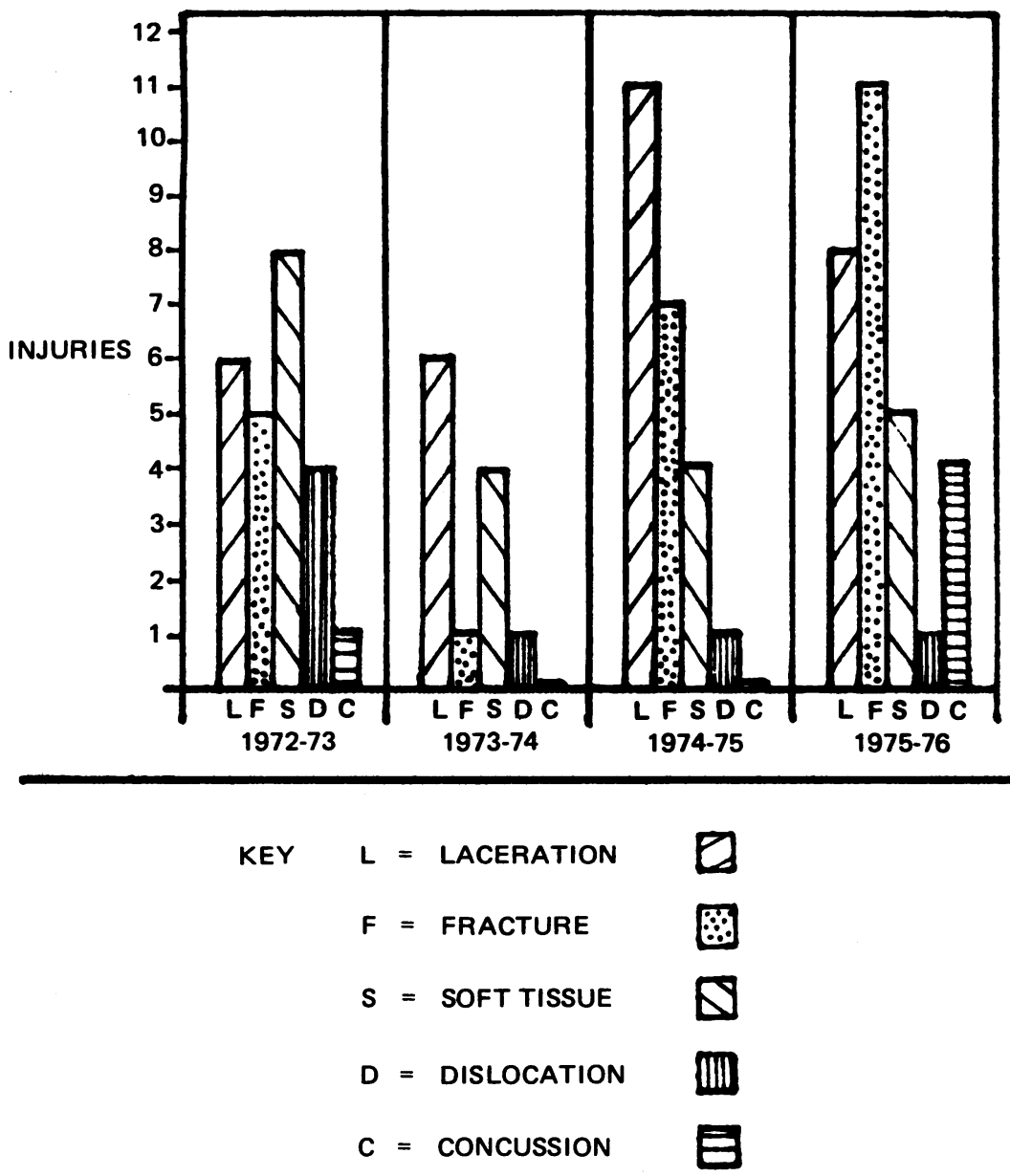

Fig. 3. Incidence of type of injury $1972-76$ 